Original Research Paper

\title{
Verification of Anchoring in Foundations of Wind Turbine Towers
}

\author{
${ }^{1}$ Nafsika Stavridou, ${ }^{1}$ Evangelos Efthymiou and ${ }^{1,2}$ Charalampos C. Baniotopoulos \\ ${ }^{I}$ Department of Civil Engineering, Institute of Metal Structures, \\ Aristotle University of Thessaloniki, Thessaloniki, Greece \\ ${ }^{2}$ School of Civil Engineering, University of Birmingham, Birmingham B15 2TT, United Kingdom
}

Article history

Received: 17-11-2015

Revised: 20-11-2015

Accepted: 20-11-2015

Corresponding Author: Nafsika Stavridou

Department of Civil Engineering, Institute of Metal Structures, Aristotle University of Thessaloniki, Thessaloniki, Greece Email: nstavrid@civil.auth.gr

\begin{abstract}
Tubular steel towers are the most common supporting structure of wind converters. The towers' foundation covers an important part of the initial cost and its configuration depends heavily on the type of subsoil. Onshore structures are founded on spread footing foundations or pile foundations with the first being the commonest. In these spread footing foundations, the tower is either embedded in the concrete foundation slab or the tower bottom flange is anchored to the concrete by means of pretensioned bolts. This anchoring of the steel tower on the concrete foundation is very rarely analyzed separately and recent failures due to inadequate design have alerted the wind industry towards the solution of the problem. For the purposes of the analytical and numerical approaches, two alternative types of foundation dimensioning are investigated. The tower properties of the two configurations are the same, providing the same loading and material data. The analytical study of the foundation anchoring is performed with the use of the equivalent ring method and the numerical verification of the two foundation solutions is performed with the use of a detailed micro model. The same micro model is used for the calculation of the fatigue life of the tower bottom joint following the damage accumulation method. In both foundation solutions, the total cross sectional area of the anchor bolts is proved to be the decisive factor for the selection of bolt size and number. The size of the tower bottom diameter plays also an important role on the maximum number and size of bolts used. Both analytical and numerical results are in good agreement and valuable outcomes are emerging from the comparative study on the foundation dimensioning of contemporary structures.
\end{abstract}

Keywords: Wind Turbine Tower, Numerical Analysis, Anchorage, Foundation, Structural Analysis

\section{Introduction}

Tubular steel wind turbine towers are the contemporary supporting structure of both on-shore and off-shore wind turbines. Since these structures consist of the on-site mounting of prefabricated subparts, the analysis and design of wind turbine foundation configurations is considered crucial for their safe construction and minimized cost. The optimization of wind turbine towers in terms of structural detailing can result in more efficient, durable and economical structures that will introduce their wider implementation leading to improvements in energy production methods and costs.
The contemporary wind farm construction cost is analyzed in the work of Blanco (2009). The tower constitutes about $25 \%$ of the total initial cost of a wind generator and the foundation construction in particular constitutes about $10 \%$ of the total initial cost for on shore structures. As it can be accessed from existing structures, the foundation design concept depends on the soil variability, but it is also observed that even in areas with similar soil types the mounting of the tower to the foundation differs between countries and manufacturers. As it can be observed in Fig. 1, spread footing foundation configurations are implemented in 
areas with stiff soils and pile foundations are preferred when there is presence of loose soils and the bedrock can be found in great depths.

Even from early stages of tower design, foundations are considered an important part of the overall wind tower design and special considerations of local soil factors are taken into account in the work of Subramanian and Vasanthi (1990). The understanding of foundation behavior is implemented in design codes related to foundations and shows great variability among different countries, although with similar wind towers and geotechnical conditions. In the work performed by Makarios and Baniotopoulos (2015), the flexibility of the soil is taken into account as partially fixed foundation, implementing the relevant continuous modelling and obtaining very accurate solutions on the dynamic response of the tower.

Various foundation types are manufactured depending on geotechnical conditions and design requirements. The simplest foundation configuration is the spread footing which is a gravity foundation that relies upon soil overburden and concrete to provide sufficient weight to resist the overturning moment due to extreme loads (Morgan and Ntambakwa, 2008). This foundation type has great applicability in various subgrade types, from soils to rock. Rock socketed and short piers foundations resist the overturning moment primarily by their bearing capacity and secondarily by the wall friction and the lateral bearing pressures. Pile foundations are commonly used in cases where the bedrock is found at great depths and the loads are counterbalanced by a combination of friction and end bearing.

Tubular steel towers, that are investigated in the present document and are widely used in nowadays wind industry, are manufactured in the factory in separate tower subsections and are connected on site by means of flanges and prestressed bolts. Complicated and costly welding work on site is avoided and quicker and more reliable assembly is reassured. The commonest foundation type of these tubular steel on-shore wind turbines is the spread footing, where the concrete foundation is casted on site and the steel tower parts are mounted on the concrete foundations. The wind tower base connects the prefabricated tower subpart to the in situ casted foundation via a connecting system. There are basically two different connecting systems as it can be observed in Fig. 1; the steel pipe with a flange which is embedded in concrete and the so called "bolt cage" where several long bolts are embedded in concrete. The first one presented in the first and third tower of Fig. 1 and the later is presented in the second and fourth. The prevailing system that is also analyzed in detail in the present work, is the one using the bolt foundation basket, which consists of a double rowed circular array of threaded steel bolts (WWEA, 2015). A retainer ring, fitted to the tower flange dimensions, is used to hold the individual bolts in position as it can be observed in the foundation drawings presented in Fig. 2. When the foundation is completed, the lower tower section is placed on the bolts protruding out of the concrete surface and then bolted with nuts and washers.

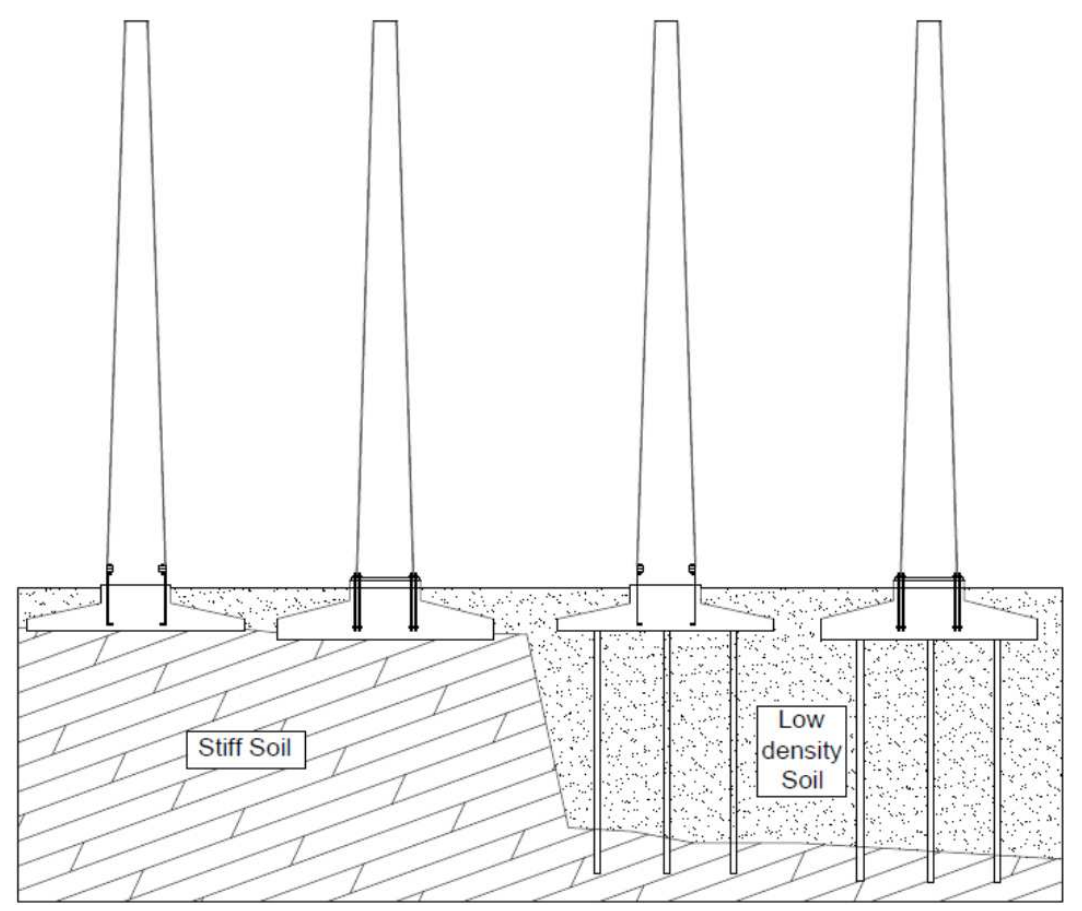

Fig. 1. Wind turbine tower foundation configurations 


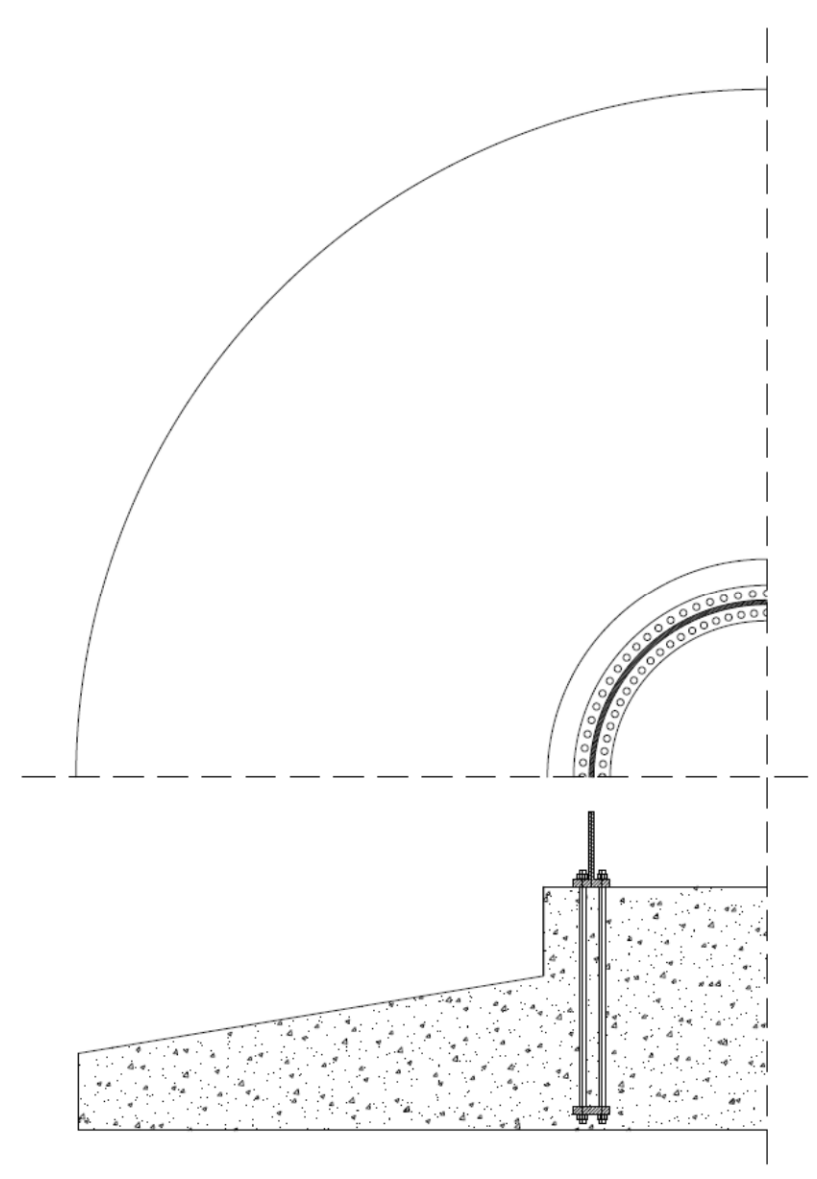

Fig. 2. Bolt cage foundation configuration

The analysis and design of a complete wind tower structure, performed by Lavassas et al. (2003) includes a detailed foundation numerical model where the anchor bolt cage has been simulated and analyzed. The anchor bolts have been simulated by cable elements, thus being checked against tension and the total anchor system shows sufficient capacity against complex loading. Eligehausen et al. (2013) performed a thorough analysis of multiple types of anchors and bolts, providing very valuable outcomes and analytical equations concerning the capacity of bolt connections on foundations. Most of the types of anchors and bolts are examined solely and in few cases results on groups of bolts are presented. Even though the special foundation configuration of wind turbine towers is not presented as a total, very important details can be borrowed from the analysis of headed studs in the above mentioned document. The case of wind turbine towers foundations shows also great similarity with nuclear power plants foundations and in the work of Ozbolt et al. (2007) experimental and numerical results of such anchors with large embedment depths are compared. The importance of the concrete cone resistance is highlighted and the pull-out resistance of the bolts is proved numerically to increase with the increase of the bolt head. To this end, the above mentioned work discusses the introduction of special factors in analytical formulas to allow for calculating the ultimate capacity of bolts with greater head sizes than the conventional. The anchorage of wind turbine towers resembles the one applied in nuclear facilities foundations. The master thesis of Eriksson and Gasch (2011) has been devoted to numerically investigate the variable failure mechanisms of bolt anchorage in concrete foundations, concluding that the finite element method is able to describe the crack propagation in these types of structures. Numerical analysis in areas of concrete where multiaxial stress states exist show that tensile forces act as a negative factor and special attention has to be drawn on concrete reinforcement and anchor design (Lindgren and Pagrotsky, 2014).

The design of such foundation types is covered in the European Standards (EC, 2004; 2005) but failures of wind towers due to structural problems continue to happen. It is stated that larger contemporary wind turbine towers fractures formed along the foundation are observed after a short operational life due to vibrations and load variations. These fractures generated even from operational loads enable water to seep through them leading to 
reinforcement bars rust and structural problems to increase (Ragheb, 2014). In the report presented by Hassanzadeh (2012), the different types of failures on wind turbine towers foundations are assessed and analysed in order to better understand the main structural problems arising in on-shore wind turbine tower construction. The analysis shows that the main reasons for the observed damages in wind turbine tower foundations is provoked due to insufficient structural design, but also execution mistakes like the one provoking cracks in mortar grout, can be found. Keeping record of wind turbine tower accidents and attempting to interpret the reasons of the failure is very instructive for reforming design guidelines. In the work of Khatri (2009) there is an attempt to include all possible failures and propose potential improvements that can be made in order to eliminate such pitfalls. The recent accident recorded in UK by Trump (2014), shows the importance of ensuring the anchorage of on shore wind turbine towers to the foundation, since bolt failures can result in total collapses of structures from their base, endangering vast areas around the tower as structures become taller.

The present work is focusing on on-shore structures founded on a circular concrete slab. The tower shell is connected to the concrete foundation by means of anchor bolts embedded in concrete and bolted to the lower tower flange. The density of the anchor bolt layout and their bearing capacity has to be investigated in order to achieve efficient foundation design. In terms of the foundation anchoring analysis presented herein, the numerical analysis of two foundation configurations consisting of anchor bolts cages is performed. The two solutions differ in diameter and bolt density and the finite element models used for the analysis are micromodels, simulating the bottom steel flange of the tower, the anchoring bolts and the concrete foundation. Finite element analysis is performed with the aid of the commercial software ABAQUS (DS, 2012) and the analytical calculation of the tower bottom joint is performed with analytical equations provided by the classic beam theory. The fatigue analysis is realized with the aid of MATLAB software following the damage accumulation method. The time-history loading data necessary for the calculation of the towers' fatigue life are artificial wind time-histories produced by National Renewable Energy Laboratory (NREL, 2015) and National Wind Technology Center (NWTC, 2015) software. The same software is used for the production of loading time histories that are employed for the fatigue assessment of bolted connections in the work of Thanasoulas et al. (2014) and welded connections in the work of Stavridou et al. (2015). Comparative results of the tower models are discussed and useful conclusions are derived on the effect of bottom diameter and anchor bolt number on the capacity of the tower bottom joint.

\section{Wind Turbine Tower Foundation Design}

\section{Foundation}

The design of wind turbine tower foundations has two discrete stages: The stability analysis and the strength analysis (Subramanian and Vasanthi, 1990). The basic parameters that it should fulfil are: Adequate stiffness and strength, stability, durability and economy. In the stability analysis the foundation configuration resists against overturning, uprooting, sliding and tilting due to soil pressure being greater than the ultimate capacity of the soil. In the strength analysis the foundation components are designed to resist to the respective maximum moment, shear, pull and their combination. The type of loading that controls the foundation design depends mainly on the kind of tower that is being designed. Different types of foundation configurations are proposed for different tower types and geotechnical data.

\section{Anchorage Design}

The typical spread footing tower anchorage assembly is two concentric rings of anchor bolts held in place at the bottom by a steel ring plate that is embedded in concrete. In Europe the embedded tower section is common whereas in the USA the anchorage cage is commoner. Building codes do not cover the design of the tower anchorage as a structural element configuration and many equations and formulas are borrowed from references in the design codes referring to steel elements that are used for concrete reinforcement and are out of scale and sometimes of different geometry compared to the tower anchorage. Designers assume first of all a volume of concrete that will pull out from the foundation upon failure at factored load levels. Two approaches exist: The shear capacity where both the strength of concrete in shear and the benefit of vertical reinforcing are included in the capacity calculations and the deep beam approach. The latter tends to result in more robust foundation anchoring due to greater reinforcement quantities along with greater comparative cost.

In the work performed by Saito et al. (2010) the anchorage capacity of the anchorage of a steel tower to the concrete foundation is attempted to be represented by a single equation which proves to have good results in correlation with the experimental ones. In design codes there is no special analytical equation given for the particular configuration and cross section of wind turbine tower foundation. Moreover, standard structural design codes do not yet cover loading generated by wind turbines, so in wind turbine tower design detailing specialized design codes need to be used such as IEC 61400-01 DNV Standards (Bonnett, 2005) and Design Guidelines by Riso (2001). Accordingly, the anchoring 
system is designed and calculated separately for each tower borrowing equations from different configurations. In the ultimate limit state, the anchor bolts are designed for the tension force imposed by the combination of axial force and bending moment referred to the bottom of the steel tube. The concept behind the ultimate limit state check of anchor bolts is that the force per unit length developed along the circular tube perimeter is transferred to the concrete by compression and to the anchor bolts in tension. Therefore in order to calculate the ultimate capacity of the anchor bolts system, the total cross section of all the anchor bolts is taken into account and in the simplified model, the total anchor cross-section is replaced by the cross-section of an equivalent steel ring. This steel ring shares the same diameter of the middle surface of the two anchor bolt layers and its thickness is equivalent to the area cross section of both bolt layers used.

In the present scientific work the ultimate capacity and fatigue life of two different wind tower foundations are assessed and compared. In ultimate limit state calculation the equivalent steel ring method is used. This simplified method replaces the two bolt layers' cross sections with a steel ring whose area cross section is the same. The diameter of this ring is identical to the diameter of the middle surface of the two bolt layers. The thickness of the steel ring is then calculated, along with its flexural inertia and flexural modulus. Taking into account the material parameters of anchor bolts class 8.8 and concrete $\mathrm{C} 40 / 50$ and the relevant ultimate limit state load factors, the maximum tension in each bolt is calculated from Equation 1:

$\sigma_{s}=\frac{\gamma_{f} \times M_{s d}}{W}-\gamma_{f} \times \frac{N_{s d}}{A_{s, t o t a l}}$

Where:

$\gamma_{f}=$ Relevant load factor

$M_{s d}=$ The moment acting at the tower foundation joint $(\mathrm{kNm})$

$W \quad=$ The flexural modulus of the equivalent steel ring

$N_{s d}=$ The normal force acting at the tower foundation joint $(\mathrm{kN})$

$A_{s}=$ The total cross section area of the equivalent steel ring

The maximum tension force on all bolts is used to compute the maximum compression on the concrete under the steel tube as follows using Equation 2 and 3:

$$
\begin{aligned}
& F=A_{s, \text { total }} \times \sigma_{s} \\
& \sigma_{c}=\frac{F}{t \times L}
\end{aligned}
$$

Where:

$\sigma_{\mathrm{c}}=$ Compression stress of concrete

$\mathrm{t}=$ The width of the bottom steel plate

$\mathrm{L}=$ The length of the middle surface of both bolt layers

The maximum tension of each bolt is checked in order not to exceed the ultimate tension strength and the maximum compression stress is checked in order not to exceed the relevant ultimate compression strength of concrete.

For the fatigue check of anchor bolts, the stress histories at the relevant structural detail is obtained from artificial loading time histories applied at the finite element model. The European Design Standard (EC, 2003) prescribes that in fatigue design, stress histories are determined from measurements on similar structures or from dynamic calculations of the structural response. Artificial loading in the case of wind turbine towers has certain advantages, since experimental data are often difficult to obtain due to the fact that the market is rather closed. Even between seemingly similar structures signal data can differ significantly, but the aerodynamic analysis performed by NREL software produces very accurate results. Loading time histories of different wind mean speeds are obtained from this software and are applied at the finite element model. The stress time-histories at the anchor bolts are calculated and the rainflow cycle counting method is then chosen in order to convert the complex stress time histories into simple cyclic loadings or stress range spectra. This conversion is performed in MATLAB software and the result of the rainflow counting method can be transformed into a spectrum of amplitudes of stress cycles in one year using the same software. Having defined the detail category (S-N curve) for the structural detail under investigation and having calculated the amplitude spectrum, the linear damage accumulation method can be practiced, using the so called Palmgren-Miner rule. The cumulated damage is given in Equation 4:

$D_{d}=\sum_{i}^{n} \frac{n_{E i}}{N_{i}}$

Where:

$n_{E i}=$ The number of cycles associated with the stress range $\gamma_{F f} \Delta \sigma_{i}$ for band $i$ in the factored spectrum

$N_{i}=$ The endurance (in cycles) obtained from the factored curve or from Equation 5 and 6 :

$N_{i}=\left(\frac{\Delta \sigma_{c}}{\Delta \sigma_{i}}\right)^{\mathrm{m}} \cdot 2 \cdot 10^{6}$, with $m=3$ for $N \leq 5 \cdot 10^{6}$ 


$$
N_{i}=\left(\frac{\Delta \sigma_{c}}{\Delta \sigma_{i}}\right)^{\mathrm{m}} \cdot 5 \cdot 10^{6}, \text { with } m=5 \text { for } 5 \cdot 10^{6} \leq N \leq 10^{8}
$$

Where:

$\Delta \sigma_{c}=$ The fatigue strength at 2 million cycles (MPa)

$\Delta \sigma_{i}=$ The stress range due to a 50 years return period wind $(\mathrm{MPa})$

The reciprocal value of the damage equals the approximated lifetime of the steel tower.

\section{Finite Element Analysis}

The present work focuses on the study of wind turbine tower foundations and more specifically on the anchorage design of steel wind turbine towers over concrete foundations. The tower that is under investigation has a hub height of $76.15 \mathrm{~m}$ and two alternative foundations solutions are compared in order to assess the analytical and numerical tools used in such structure configurations. The tower has been designed and analyzed by Veljkovic et al. (2006) and its structural behavior has been verified in the Thesis of Bzdawka (2011). Tubular steel towers like the one investigated in the present work have a tapered diameter increasing from top to bottom and a stepwise increasing shell thickness from top to bottom again. The top diameter of the initial [I] tower and the alternative tower [II] is $3 \mathrm{~m}$, while the foundation diameter is $4.3 \mathrm{~m}$ for the initial tower and $4.0 \mathrm{~m}$ for the alternative one. Shell thicknesses and diameters along the height of the towers can be observed in Table 1. The number of bolts and their mechanical characteristics differ between the two tower solutions as it can be observed in Fig. 3.

The loads acting on the tower foundations are the same and the effect of the bottom diameter on anchor design is discussed.

\section{Materials and Loads}

The steel tubular wind turbine tower material is S355 and since in all the analyses the stress levels remain at the elastic range, no hardening is taken into account in the material law and a simple stable plateau is only used in case some elements enter plasticity.

When designing the lower part of wind turbine towers, the ultimate limit state is dominant (Baniotopoulos and Stathopoulos, 2007) and in this limit state analysis the static loads incorporated, correspond to the extreme wind load combination provided by the manufacturer of the nacelle. The machinery in both tower cases is the same, so the ultimate limit state loads that are deriving from the rotor motion are the same: The horizontal force of $\mathrm{F}=75,5 \mathrm{kN}$ and the horizontal axis moment of $\mathrm{M}=1091 \mathrm{kNm}$. The tower weight is assumed to be the same.
Table 1. Tower shell thicknesses and diameters along the tower height

\begin{tabular}{|c|c|c|c|c|}
\hline \multirow[b]{2}{*}{$\mathrm{Z}(\mathrm{m})$} & \multicolumn{2}{|c|}{ Diameters $(\mathrm{m})$} & \multirow{2}{*}{$\begin{array}{l}\text { Shell } \\
\text { thickness } \\
(\mathrm{mm})\end{array}$} & \multirow[b]{2}{*}{ Tower } \\
\hline & $\begin{array}{l}\text { Tower } \\
{[\mathrm{I}]}\end{array}$ & $\begin{array}{l}\text { Tower } \\
{[\mathrm{II}]}\end{array}$ & & \\
\hline 76.15 & 3.00 & 3.00 & 18 & \\
\hline 73.14 & 3.02 & 3.05 & 14 & \\
\hline 69.67 & 3.04 & 3.10 & 12 & \\
\hline 65.79 & 3.12 & 3.15 & 12 & \\
\hline 62.27 & 3.20 & 3.20 & 13 & \\
\hline 58.85 & 3.27 & 3.25 & 13 & \\
\hline 55.24 & 3.35 & 3.30 & 14 & \\
\hline 51.89 & 3.42 & 3.32 & 15 & \\
\hline 48.40 & 3.50 & 3.35 & 16 & \\
\hline 45.08 & 3.55 & 3.38 & 17 & \\
\hline 41.75 & 3.60 & 3.40 & 17 & \\
\hline 38.43 & 3.65 & 3.42 & 18 & \\
\hline 35.10 & 3.70 & 3.45 & 19 & \\
\hline 31.78 & 3.75 & 3.48 & 19 & \\
\hline 28.45 & 3.80 & 3.50 & 20 & \\
\hline 25.13 & 3.85 & 3.55 & 20 & \\
\hline 21.80 & 3.90 & 3.60 & 21 & \\
\hline 19.08 & 3.95 & 3.65 & 22 & \\
\hline 16.35 & 4.00 & 3.70 & 22 & \\
\hline 13.63 & 4.05 & 3.75 & 23 & \\
\hline 10.90 & 4.10 & 3.80 & 24 & \\
\hline 8.18 & 4.15 & 3.85 & 27 & \\
\hline 5.45 & 4.20 & 3.90 & 26 & \\
\hline 2.73 & 4.25 & 3.95 & 30 & \\
\hline 0.00 & 4.30 & 4.00 & & \\
\hline
\end{tabular}

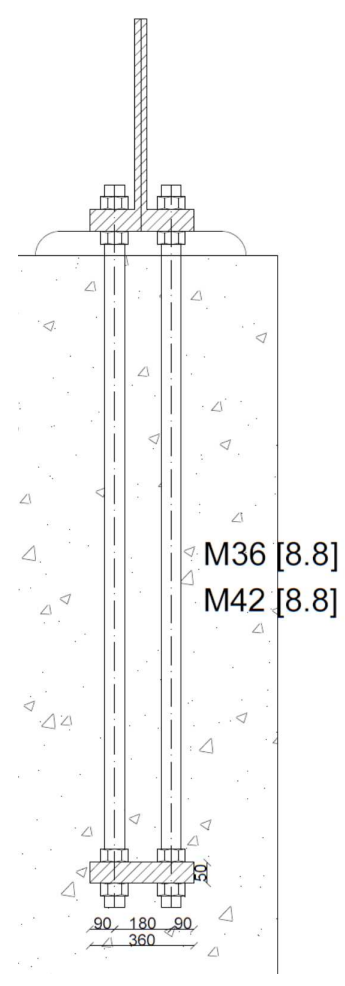

Fig. 3. Anchorage structural detail 
For the fatigue analysis, the loading time-histories are produced with the aid of NREL and NTWC freeware; Turbsim, Fast and Aerodynand for time and data saving reasons only the two major loading histories at the top of the tower are taken into account. The weight of the tower is neglected in the fatigue analysis. The above mentioned time-histories correspond to variable mean wind speeds in order to cover all the spectrum of operational winds. The time-histories incorporated in the present analysis are for a wind of turbulence level $\mathrm{B}$ and according to Kaimal frequency spectrum. There are six different time histories corresponding to mean wind speeds of 2 , $6,10,14,18$ and $22 \mathrm{~m} \mathrm{sec}^{-1}$. The loading histories are applied at the tower hub height to a reference point eccentrically located simulating the exact rotor position. This position is shifted horizontally $+0.725 \mathrm{~m}$ from the axis of the tower and vertically $+0.50 \mathrm{~m}$ above the upper flange level $(+76.15 \mathrm{~m})$.

\section{Results}

\section{Ultimate Capacity Results}

The method followed to calculate the ultimate capacity of the tower bottom joint is described earlier in the present document. The initial foundation solution consists of 160 M42 (8.8) bolts, thus 2 layers of 80 M42 bolts. The diameter of the middle surface of the two bolt layers is 4.0 $\mathrm{m}$ and the maximum tension applied in each bolt is calculated in Table 2. The ultimate tension for bolts is 576 $\mathrm{MPa}$ and is calculated from Equation 7 as follows:

$$
\sigma_{u}=\frac{\gamma_{f} \times f_{u k}}{\gamma_{\mathrm{M} 2}}
$$

Where:

$\gamma_{f}=$ Relevant load factor $f_{u k}=$ The rupture tension $(\mathrm{MPa})$

$\gamma_{M 2}=$ The safety coefficient

From Table 2 it is shown that when the diameter of the bolt layer mid surface increases with the total bolt cross section remaining the same, there is an increase in the flexural modulus and therefore the developing bolt tensile stress decreases. That way, when using larger diameters bolts with smaller cross sectional area can be used offering the same flexural mobulus with economy in material and initial construction cost. The calculation of the maximum compressive stress of the concrete under the steel tube is presented in Table 3. Again when increasing the bottom tower diameter, there is a relief in the compressive stresses developed in the concrete under the steel tube but the difference is not significant between the different bolts size solutions. In all cases the developed compressive stress is lower than the ultimate concrete compressive stress for concrete $(\mathrm{C} 40 / 50)$ used. The increase in the tower diameter allows for the use of smaller number of bolts and the calculation of maximum tension of the anchor bolts in that case is presented in Table 4 with the use of 130 bolts ( 2 layers of 75 bolts) instead of 160 .

\section{Fatigue Life Calculation Results}

The fatigue life assessment of the anchor bolts is based on the calculation of the stress history $\sigma_{\mathrm{zz}}$ at the tower anchor where the maximum tensile stresses appear. This stress history is produced from the artificial time history loading applied at the tower hub height. The normal stresses developed at the anchor bolts position are obtained from numerical analyses of the two foundation solutions for variable wind mean speeds in order to cover all the range of normal operating conditions.

Table 2. Calculation of maximum tension in the anchor bolts

\begin{tabular}{|c|c|c|c|c|c|c|c|c|}
\hline \multicolumn{2}{|l|}{ Loading data } & \multirow{2}{*}{$\begin{array}{l}\text { Bolts } \\
\text { size }\end{array}$} & \multicolumn{3}{|c|}{ Tower [I] } & \multicolumn{3}{|c|}{ Tower [II] } \\
\hline Msd (kNm) & Nsd (kN) & & As $\left(\mathrm{m}^{2}\right)$ & $\mathrm{W}\left(\mathrm{m}^{3}\right)$ & $\sigma_{\mathrm{s}}(\mathrm{MPa})$ & As $\left(m^{2}\right)$ & $\mathrm{W}\left(\mathrm{m}^{3}\right)$ & $\sigma_{\mathrm{s}}(\mathrm{MPa})$ \\
\hline 59715 & 2751 & M36 & 0.156160 & 0.1558 & 502.53 & 0.156160 & 0.1811 & 430.00 \\
\hline 59715 & 2751 & M42 & 0.179360 & 0.1797 & 435.70 & 0.179360 & 0.2076 & 375.07 \\
\hline 59715 & 2751 & M48 & 0.235680 & 0.2362 & 331.40 & 0.235680 & 0.2716 & 286.74 \\
\hline
\end{tabular}

a. Msd is the design moment, Nsd is the design vertical force, As is the total bolt cross section area, $\mathrm{W}$ is the flexural modulus of the equivalent steel ring, $\sigma_{\mathrm{s}}$ is the maximum tension developed in each bolt of the connection

Table 3.Maximum compression stress developed in concrete

\begin{tabular}{|c|c|c|c|c|c|c|c|c|}
\hline \multicolumn{2}{|l|}{ Loading data } & \multirow{2}{*}{$\begin{array}{l}\text { Bolts } \\
\text { size }\end{array}$} & \multicolumn{3}{|c|}{ Tower [I] } & \multicolumn{3}{|c|}{ Tower [II] } \\
\hline Msd (kNm) & Nsd $(\mathrm{kN})$ & & $\mathrm{F}(\mathrm{kN})$ & $\mathrm{L}(\mathrm{m})$ & $\sigma_{\mathrm{c}}(\mathrm{MPa})$ & $\mathrm{F}(\mathrm{kN})$ & $\mathrm{L}(\mathrm{m})$ & $\sigma_{\mathrm{c}}(\mathrm{MPa})$ \\
\hline 59715 & 2751 & M36 & 78475 & 12.57 & 18.37 & 67149 & 13.51 & 14.62 \\
\hline 59715 & 2751 & M42 & 78147 & 12.57 & 18.29 & 67271 & 13.51 & 14.65 \\
\hline 59715 & 2751 & M48 & 78105 & 12.57 & 18.27 & 67578 & 13.51 & 14.71 \\
\hline
\end{tabular}

a. Msd is the design moment, Nsd is the design vertical force, $\mathrm{F}$ is the maximum compression force of all bolts, $\mathrm{L}$ is the length of the mid surface of the equivalent steel ring, $\sigma_{c}$ is the maximum compressive stress developed in the concrete foundation 
Table 4. Calculation of maximum tension in the anchor bolts [130 anchor bolts]

\begin{tabular}{|c|c|c|c|c|c|c|c|c|}
\hline \multirow{2}{*}{$\begin{array}{l}\text { Loading data } \\
\text { Msd (kNm) } \\
\end{array}$} & \multirow{2}{*}{$\begin{array}{l}\text { Bolts } \\
\text { Nsd }(\mathrm{kN}) \\
\end{array}$} & \multirow[b]{2}{*}{ Size } & \multicolumn{3}{|l|}{ Tower [I] } & \multicolumn{3}{|l|}{ Tower [II] } \\
\hline & & & As $\left(m^{2}\right)$ & $\mathrm{W}\left(\mathrm{m}^{3}\right)$ & $\sigma_{\mathrm{s}}(\mathrm{MPa})$ & As $\left(m^{2}\right)$ & $\mathrm{W}\left(\mathrm{m}^{3}\right)$ & $\sigma_{\mathrm{s}}(\mathrm{MPa})$ \\
\hline 59715 & 2751 & M36 & 0.126880 & 0.1269 & 616.92 & 0.126880 & 0.1467 & 530.70 \\
\hline 59715 & 2751 & M42 & 0.145730 & 0.1457 & 537.14 & 0.145730 & 0.1686 & 461.90 \\
\hline 59715 & 2751 & M48 & 0.191490 & 0.1910 & 409.96 & 0.191490 & 0.2217 & 351.29 \\
\hline
\end{tabular}

a. Msd is the design moment, Nsd is the design vertical force, As is the total bolt cross section area, $\mathrm{W}$ is the flexural modulus of the equivalent steel ring, $\sigma_{\mathrm{s}}$ is the maximum tension developed in each bolt of the connection
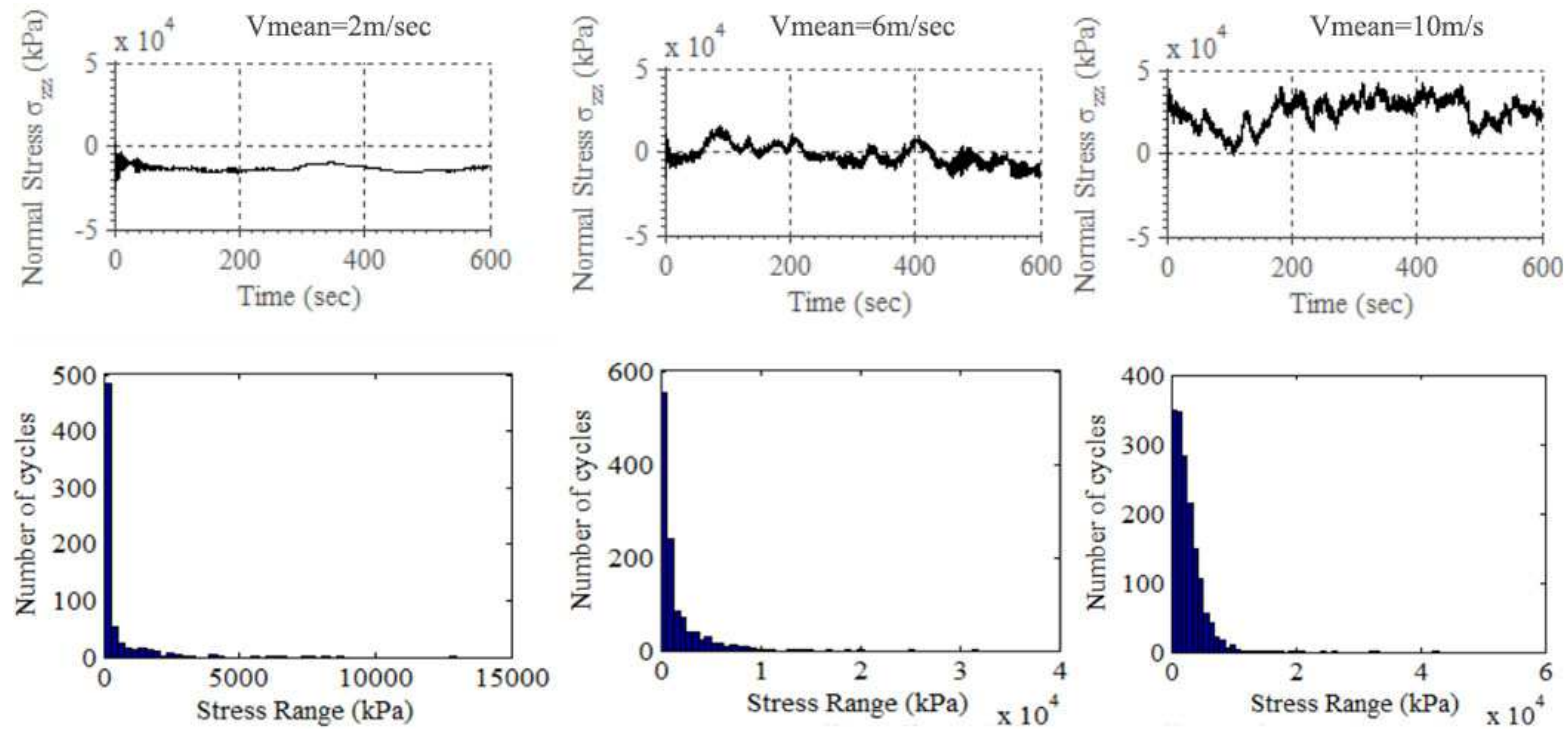

Fig. 4. Tower I- Conversion of Tensile stress histories to stress range histograms for 2, 6, $10 \mathrm{~m} \mathrm{sec}^{-1}$ mean wind speed
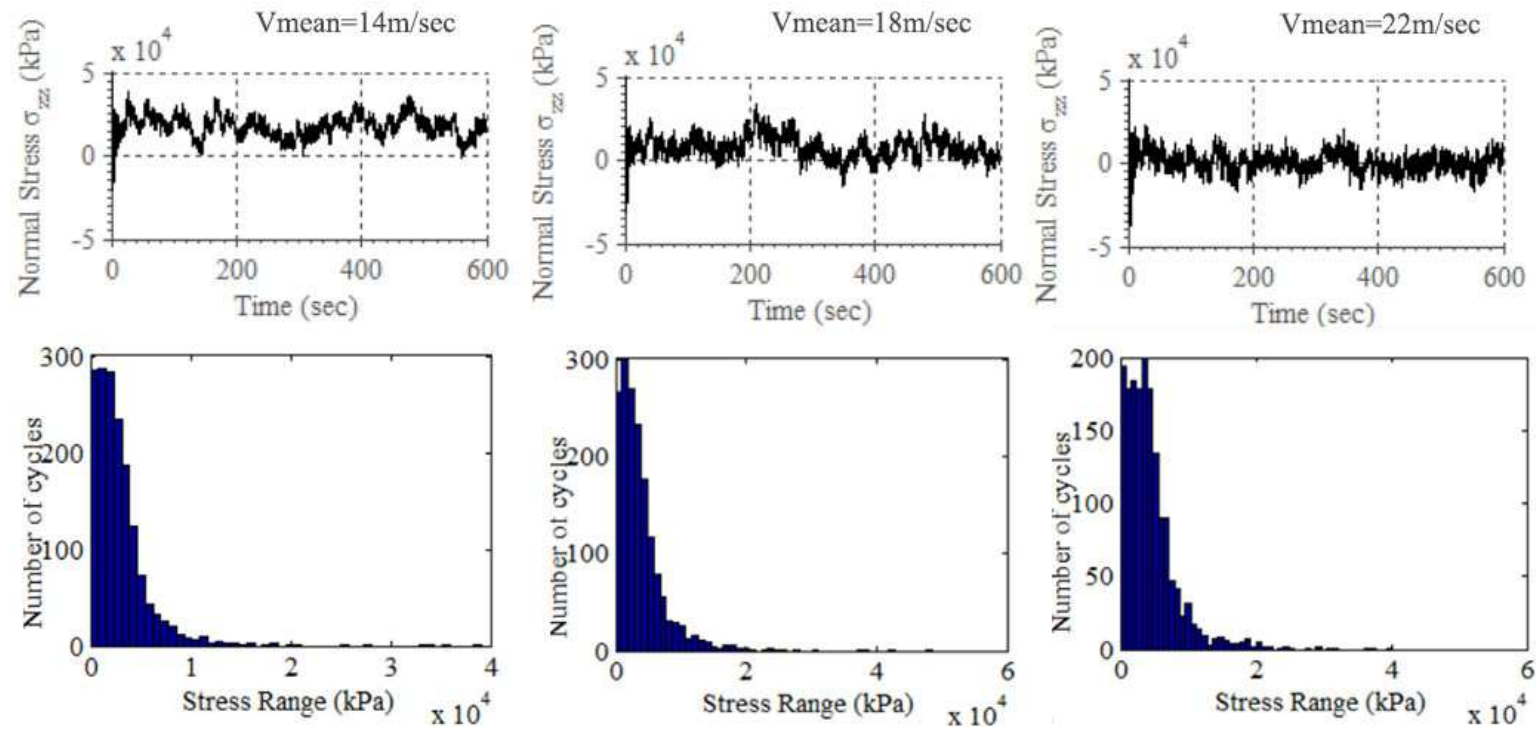

Fig. 5. Tower I- Conversion of Tensile stress histories to stress range histograms for 14, 18, $22 \mathrm{~m} \mathrm{~s}^{-1}$ mean wind speed

The stress histories at the structural detail under investigation are transformed to stress range spectra by following the rainflow cycle counting method in MATLAB software. In Fig. 4 and 5 the conversion of the stress histories $\sigma_{z z}$ to stress range histograms for Tower Iis presented for the six different mean wind speeds. In Fig. 6 and 7 the same conversion of stress histories to stress range histograms for Tower II bolt anchorage are 
presented. The stress histories are time-dependent, with variable frequencies and ranges and therefore difficult to assess, while in stress range histograms the stress ranges are associated with the relevant number of cycles. The complex stress time histories are converted to histograms of number of cycles and stress levels by converting the simple time history to simple cyclic loading and by picking the peaks for tensile and the valleys for compressive stresses through the rainflow method. This transformation from is realized in the environment of matlab software and is presented for the two towers in the above mentioned figures.

The stress range spectra present the stress ranges and the relevant number of cycles in descending order for each one of the six mean wind speeds. Since the fatigue check is referring to normal operating conditions, the first $10 \mathrm{sec}$ of the loading and stress time histories are neglected in the analysis due to the presence of signal noise deriving from the launching of the machinery. The stress range spectra of the different mean wind speeds refer to the $10 \mathrm{~min}$ wind loading. In order to calculate the fatigue life of the structure the $10 \mathrm{~min}$ stress range histograms are scaled to annual stress range histograms. This is realized by summing the cycles of each $10 \mathrm{~min}$ wind multiplied by the relevant probability of occurrence, multiplied by the number of $10 \mathrm{~min}$ durations in one year. According to IEC 61400-1 (IEC, 2005) the distribution of wind speeds over an extended period of time like a year's time, can be expressed by the Rayleigh distribution.
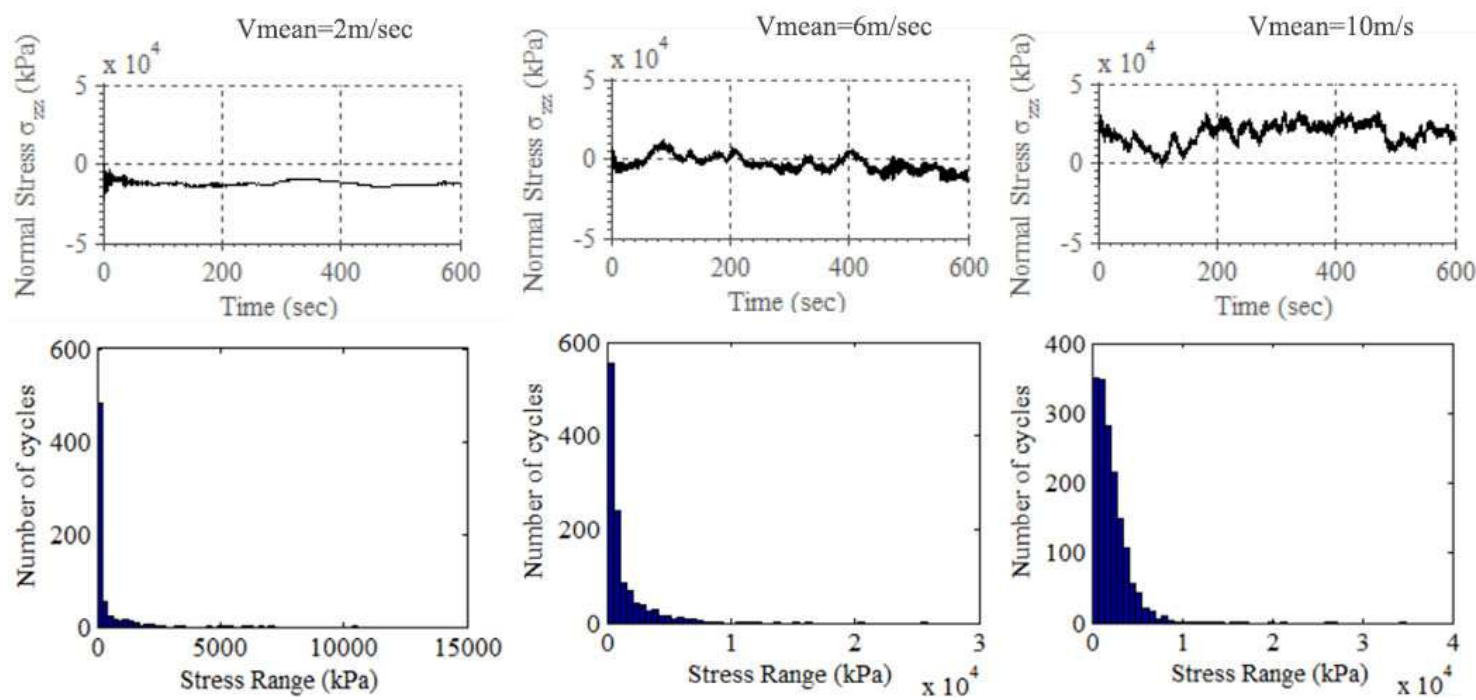

Fig. 6. Tower II- Conversion of Tensile stress histories to stress range histograms for 2, 6, $10 \mathrm{~m} \mathrm{sec}^{-1}$ mean wind speed
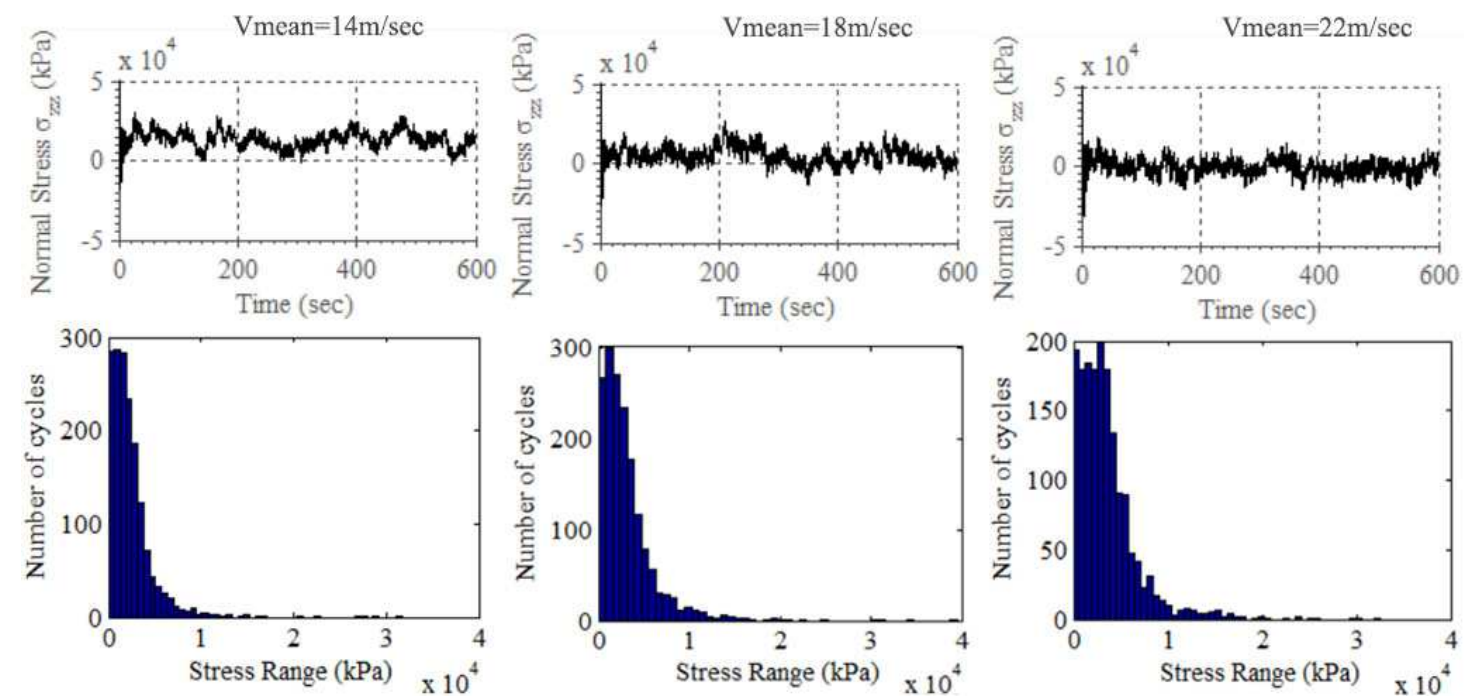

Fig. 7. Tower II- Conversion of Tensile stress histories to stress range histograms for $14,18,22 \mathrm{~m} \mathrm{sec}^{-1}$ mean wind speed 


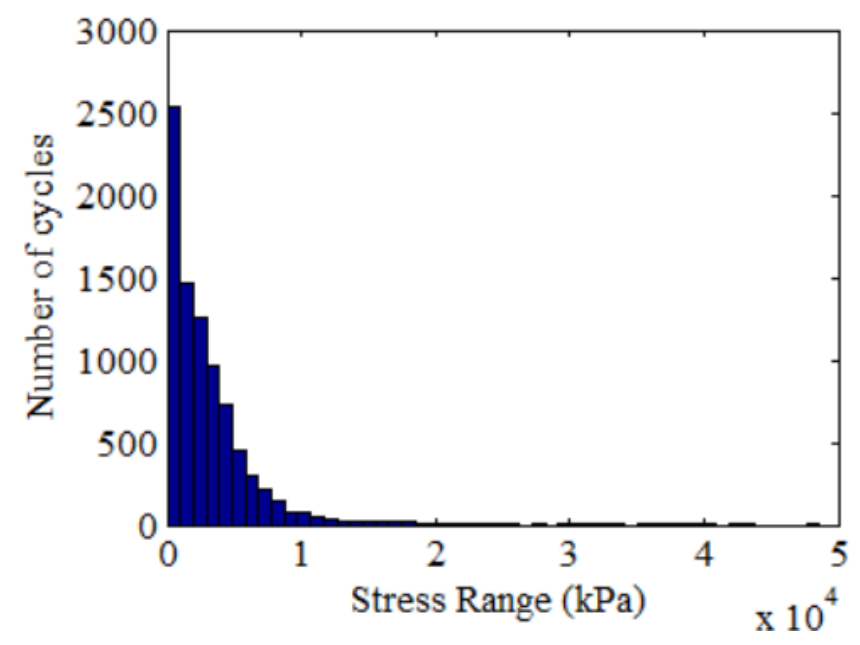

Fig. 8. Tower I -annual stress range histogram

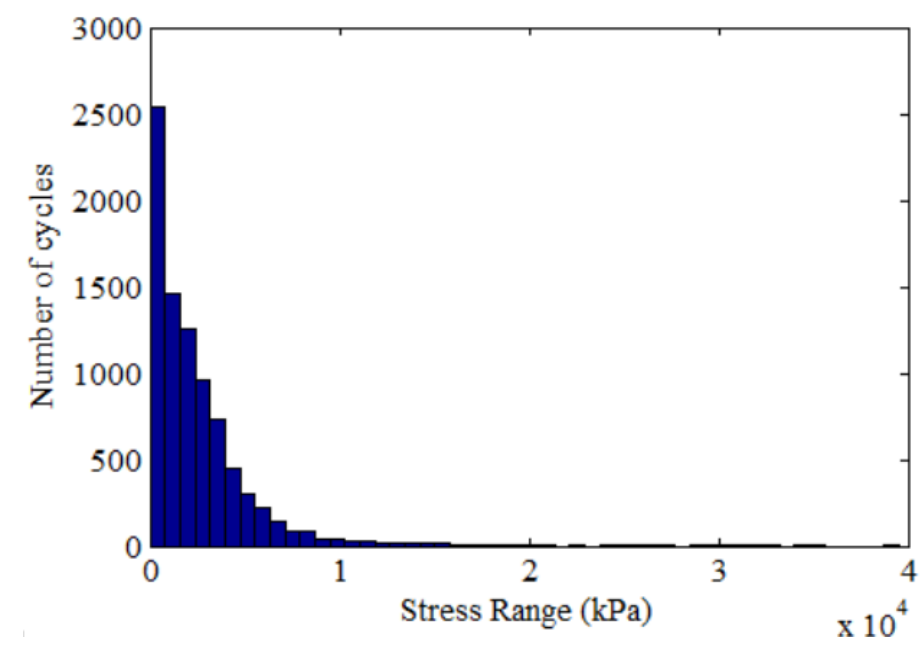

Fig. 9. Tower II -annual stress range histogram

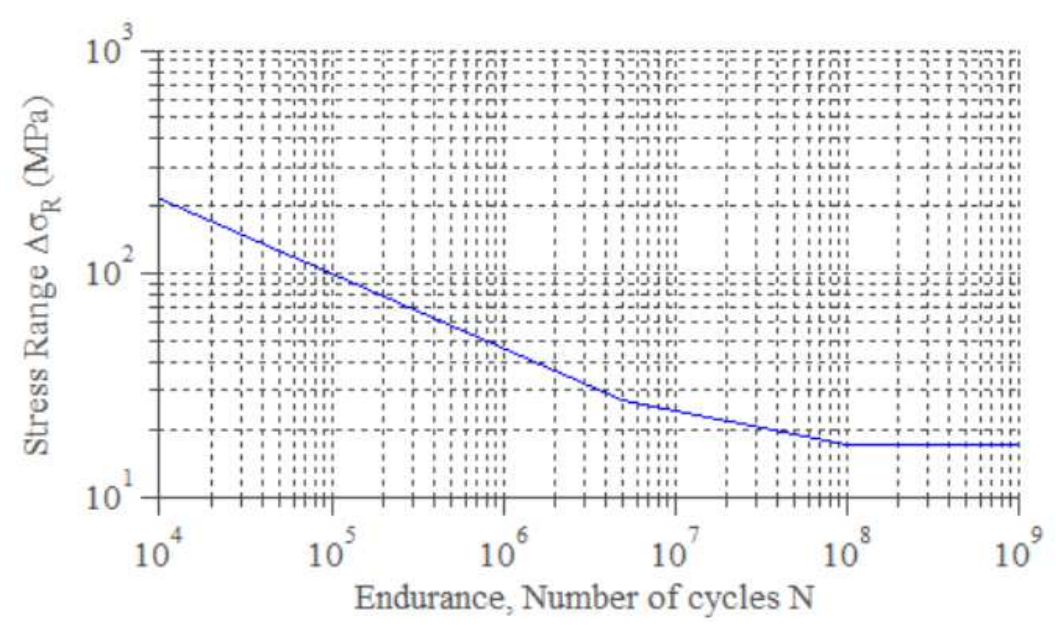

Fig. 10. Direct stress range over endurance for $\Delta \sigma=50 \mathrm{MPa}$ 
Taking into account the probability of occurrence calculated from the Rayleigh distribution and the stress range histograms for each $10 \mathrm{~min}$ wind, the annual stress range spectrum for the towers is calculated and presented in Fig. 8 and 9.

The fatigue life of the towers is calculated following the damage accumulation method, which means that the material does not recover when it is unloaded. For the damage calculation the assumption of linear damage accumulation is taken into account and the Palmgren-Miner rule is used. The linear damage accumulation scheme assumes that stress ranges, occurring $n i$ times results in a partial damage that is represented by a ratio $\mathrm{ni} / \mathrm{Ni}$ where $\mathrm{Ni}$ is the number of cycles to failure.

The failure of each structural detail is calculated by summing all the partial damages deriving from each load level occurring for a certain number of cycles. The detail category that corresponds to the connection with anchor bolts to the concrete slab is categorized according to EN 1993-1-9 (EC, 2003) in the group of bolts subjected to tension and has a fatigue stress capacity of $\Delta \sigma c=50 \mathrm{MPa}$. The factored capacity curve that corresponds to the structural detail under consideration is presented in Fig. 10.

In order to assess a structure's capacity against fatigue, the fatigue check of the selected structural detail is performed by ensuring that the cumulative damage D defined in Equation 4 should be lower than the theoretical value of 1 when damage occurs. The annual cumulative damage for Tower I when checking the anchor bolt foundation is 0.0323 and for Tower II is 0.0124 . The fatigue check criterion is fulfilled for both towers and the fatigue life which is calculated by $1 / \mathrm{D}$ is 35 years for the first tower and 80 years for the second with bigger bottom diameter. This shows that both towers are well designed, since the fatigue criterion is fulfilled. The increase in the tower foundation diameter without increasing either the number or the bolt cross-section area signifies a longer fatigue life of the detail and the tower as a whole. This shows that the tower diameter is a decisive factor for the fatigue life of the structure and the particular structural detail under consideration is a very important one since it present rather low fatigue life estimation, requiring very careful construction and rather frequent maintenance works.

\section{Conclusion}

The present work investigates the effect of wind turbine tower bottom flange diameter, on the capacity of the tower anchorage to the foundation. The numerical models of different diameter size are assessed as far as ultimate capacity and fatigue life are concerned. The results signify that the increase in diameter with the same number and cross section area of the anchor bolts, increase the moment of inertia along with the flexural modulus of the cross section. This increase lowers the tensile stress developing in the bolt, which allows for the use of smaller bolt size or lower bolt number. On the other hand, when assessing the fatigue life of the two foundation solutions, there is a small increase in the bottom tower diameter in the level of $7.5 \%$. The total length perimeter of the tower bottom differs between the two solutions about $11 \%$. As calculated in the results, the fatigue life of Tower I with smaller bottom diameter is 33 years and for Tower II with larger is 80 years. The increase in the fatigue life of the structure is about $60 \%$ with the increase in the bottom diameter being very small. The increase in the bottom tower diameter increases the flexural modulus and moment of inertia significantly without increasing the bolt number and bolt size, therefore providing a better tower structural response without resulting in higher construction cost. Moreover, bigger tower bottom diameter allows for the use of smaller size bolts or smaller number of anchor bolts, permitting a lower initial construction cost. Finally, in both foundation configurations, the fatigue life of the structure is satisfactory indicating that both solutions are feasible and safe and the optimized tower diameter influences only the initial construction cost.

\section{Acknowledgement}

The first author wants to express her gratitude to IKY for financial support of the research activities on performing her PhD thesis through the IKY Fellowship of Excellence for Postgraduate Studies in Greece SIEMENS Program.

This research has been co-financed by the European Union (European Social Fund-ESF) and Greek national funds through the Operational Program "Education and Lifelong Learning" of the National Strategic Reference Framework (NSRF)-Research Funding Program: THALES: Reinforcement of the interdisciplinary and/or inter-institutional research and innovation.

\section{Funding Information}

The first author's PhD thesis and research activity is financially supported by the IKY Fellowship of Excellence for Postgraduate Studies in GreeceSIEMENS Program. 
This research has been co- financed by the European Union (European Social Fund-ESF) and Greek national funds through the Operational Program "Education and Lifelong Learning" of the National Strategic Reference Framework (NSRF) -Research Funding Program: THALES: Reinforcement of the interdisciplinary and/or inter-institutional research and innovation.

\section{Author's Contributions}

All the authors of this manuscript contributed equally to the preparation, development and publication of the scientific work.

\section{Ethics}

The authors confirm that this article is original and contains previously unpublished material. The corresponding author verifies that other authors have read and approved the manuscript and no ethical issues are violated.

\section{References}

Baniotopoulos, C.C. and T. Stathopoulos, 2007. Wind Effects on Buildings and Design of WindSensitive Structures. 1st Edn., Springer Science and Business Media, New York, ISBN-10: 3211730761, pp: 230.

Blanco, M.I., 2009. The Economics of wind energy. Renewable Sustainable Energy Rev., 13: 1372-1382. DOI: 10.1016/j.rser.2008.09.004

Bonnett, D., 2005. Wind turbine foundations-loading, dynamics and design. Structural Engineer, 83: 41-45.

Bzdawka, K., 2011. Structural analysis of a wind turbine tower-steel tubular towers of heights: $76.15 \mathrm{~m}$ and 105.0m. MSc Thesis, Poznan University of Technology.

DS, 2012. Abaqus analysis user's manual. Dassault Systemes. Abaqus 6.12, Providence, RI, USA.

EC, 2003. Eurocode 3: Design of steel structures-part 19: Fatigue. European Commission, CEN, Brussels, Belgium.

EC, 2004. Eurocode 2: Design of concrete structures-part 1-1: General rules and rules for buildings. European Commission, CEN, Brussels, Belgium.

EC, 2005. Eurocode 3: Design of steel structures-Part 18: Design of joints. European Commission, CEN, Brussels, Belgium.

Eligehausen, R., R. Mallee and J.F. Silva, 2013. Anchorage in concrete construction. John Wiley and Sons, USA, ISBN-10: 3433601380, pp: 391.
Eriksson, D. and T. Gasch, 2011. Load capacity of anchorage to concrete at nuclear facilities. MSc Thesis, KTH Architecture and the Built Environment, Stockholm, Sweden.

Hassanzadeh, M., 2012. Cracks in onshore wind power foundations Causes and consequences. Published Technical Report, Elforsk, Stockholm, Sweden.

IEC, 2005. Wind turbines-Part 1: Design requirements. International Electrotechnical Commission, Geneva, Switcherland.

Khatri, D., 2009. Structural failures of wind towers and dynamic analysis procedures. URS Corporation, Los Angeles, USA.

Lavassas, I., G. Nikolaidis, P. Zervas, E. Efthymiou and I.N. Doudoumis et al., 2003. Analysis and design of the prototype of a steel 1-MW wind turbine tower. Eng. Structures, 25: 1097-1106. DOI: 10.1016/S0141-0296(03)00059-2

Lindgren, A. and O. Pagrotsky, 2014. Numerical analysis of wind power plant foundations. MSc Thesis, Chalmers University of Technology, Goteborg, Sweden.

Makarios, T. and C.C. Baniotopoulos, 2015. Modal analysis of wind turbine tower via its continuous model with partially fixed foundation. Int. J. Innovative Res. Adv. Eng., 2: 14-25.

Morgan, K. and E. Ntambakwa, 2008. Wind turbine foundation behavior and design considerations. Proceedings of the AWEA Wind Power Conference AWEA, (AWEA’ 08), Houston, USA.

NREL, 2015. National Renewable Energy Laboratory.

NWTC, 2015. National Wind Technology Center.

Ozbolt, J., R. Eligehausen, G. Periskic and U. Mayer, 2007. 3D FE analysis of anchor bolts with large embedment depths. Eng. Fracture Mechan., 74: 168-178. DOI: 10.1016/j.engfracmech.2006.01.019

Ragheb, M., 2014. Safety of wind systems. Wind Power Systems Course Material, University of Illinois at Urbana-Champaign, USA.

Riso, 2001. Guidelines for design of wind turbines. Det Norske Veritas, Copenhagen, Denmark.

Saito, S., T. Kamimoto and K. Yui, 2010. Experimental and Analytical Study on Anchorage Capacity Between Single-Pole Tower and RC Foundation. In: Fracure Mechanics of Concrete and Concrete Structures-Assessment, Durability, Monitoring and Retrofitting of Concrete Structures, Oh, B.H., O.C. Choi, L. Chung and K. Concrete Institute (Eds.), Korea Concrete Institute, Seoul, Korea, ISBN-10: 895708181X, pp: 843-851. 
Stavridou, N., E. Efthymiou and C.C. Baniotopoulos, 2015. Welded connections of wind turbine towers under fatigue loading: Finite element analysis and comparative study. Am. J. Eng. Applied Sci. DOI:10.3844/ofsp.10076

Subramanian, N. and V. Vasanthi, 1990. Design of tower foundations. Concrete J., 64: 135-141.

Thanasoulas, I., K.G. Koulatsou and C.J. Gantes, 2014. Nonlinear numerical simulation of the response of bolted ring flanges in wind turbine towers. Proceedings of the 8th Hellenic National Conference of Steel Structures, Oct. 2-4, Metal Structures Research Society, Greece, pp: 159-159.
Trump, S., 2014. The scandal of UK's death-trap wind turbines: A turbine built for $115 \mathrm{mph}$ wind felled in $50 \mathrm{mph}$ gusts. Mail Online.

Veljkovic, M., C. Heistermann and W. Husson, 2006. High-strength tower in steel for wind turbines. Published Technical Report, Publications Office of the European Union, Brussels, Belgium

WWEA, 2015. Tower and foundation: An example. World Wind Energy Association. 